\title{
Phenomenological Enquiry Into the Public Misconceptions of Billboard Design Concepts in Lagos, Nigeria: The Factor Analytic Approach
}

\author{
Femi Kayode \\ Department of Industrial Design, Federal University of Technology, Akure, Nigeria
}

Email address:

ofkayode@futa.edu.ng

To cite this article:

Femi Kayode. Phenomenological Enquiry Into the Public Misconceptions of Billboard Design Concepts in Lagos, Nigeria: The Factor Analytic Approach. International Journal of Economic Behavior and Organization. Vol. 3, No. 3, 2015, pp. 47-54.

doi: 10.11648/j.ijebo.20150303.14

\begin{abstract}
Multiple and Dense line-up of billboard structures in Lagos metropolis and highways suggestthat the outdoor advertising business is increasing in quantity, quality and patronage. Continuous population explosion, industrial development and urban renewal efforts of Lagos State government occasion the advertising agencies to introduce creative techniques. However, misconceptions about outdoor creative concepts reflect a worrisome trend. The industry is criticized to be responsible for the influx of negated vogues as well as the mixed brew of foreign and Nigerian indigenous cultures through its creative design concepts. This study undertakes a critical enquiry into the factors responsible for public misconceptions and misgivings about outdoor advertisements. The study adopted survey research design. The instrument used to collect data was questionnaire which comprised of thirty-three variables numbered from b48-b80. The population for the study comprised of the seventy-eight outdoor and eighty-eight conventional advertising agencies, seventy-two advertisers, sixty-one graphic designers and three hundred and eighty-five end-users. The procedure for data collection included Pilot Study and Validity test of the instrument. Non-parametric test method, by way of Factor Analysis was used to analyze the data collected and carry out factor extraction by principal component. The thirty-three (33) variables were reduced to ten (10) common factors through principal component analysis.
\end{abstract}

Keywords: Advertising, Critics, Materialism, Misconceptions, Factor Extraction, Multi-Cultural

\section{Introduction}

Billboard advertising shows no trace of losing momentum in the whole of Lagos metropolis. The multiplicity of billboard structures in open spaces and express roads is vivid and incontestable evidence. No two products are the same or saying the same thing to the spectators when their design concepts are examined. The public can interact with it and thus have the pleasure that they are part of the information society. Its popularity depends largely on the lustre that the advertising agency added to the visual contact involved (Precourt, 2013, Hess and Doe, 2013). It therefore seems unrealistic to proffer that people are not influenced by what they see in the open spaces. The synergy between billboard structures and the urban space system should continue unabated. The correlation matrix between them should deliver duo results. First, it should speak and sell products to the audience and second, it should give optical improvement to environmental quality. A genuine concern arises from here because what goes on in the landscapes, and by extension, our cities is very much an expression of our social, cultural and aesthetic civilization.Besides, billboard advertisements in city parks and other open spaces are not only a visual plus, it is an indicator for dynamic commercial activities remembering the amount of commercial business concepts put into it and money spent to look for money. Advertising, as noted in Schneider (2007), is all about communication between a company and its current, potential and, or former customers. It is one of the institutions through which sales of goods and rendition of services are made (Jobber and Lancaster, 2009). In marketing consumer goods and services, branding is of the essence and advertising is generally thought of to be most effective promotional tool for the task.

An upsurge of interest is noticed in the roles of outdoor advertising as mass communicator in business markets (Hess and Doe, 2013). It can also be deduced from the billboard 
concepts displayed in public places that the industry keeps active and creative people in employment. In Biemans (2010), it is noted that the driving force behind a country's economy are the millions of business transactions that need to be communicated to a group of customers or other related stakeholders. Billboard advertisements therefore merit this onerous task of providing same message(s) to a large number of audiences. The heterogeneous mix of organic ideas and creative techniques from the advertising agencies portend dynamism for the outdoor signage business. In a densely crowded marketplace like Lagos, industries, institutions and private business concerns remain the different commercial facets which compete to distinguish themselves and protect their existence. The panoply of outdoor advertising firms with core competencies in captivating pictorial designs and messages with force of persuasion are an essential reference point for the expression of new brand of products and revitalization of existing ones. Be that as it may, many advertising critics have thrown these understanding overboard, holding wrong understanding of the dimensions of the creative imperatives needed to capture the different target audiences. This is a commonplace in a multi-cultural society like Lagos. Perhaps, visual design illiteracy and sentimental views that are imminent in the perception of the heterogeneous mix of the Lagos populace have heightened to act as catalyst for the seemingly unresolved conflict of impressions that still lingers against the billboard design concepts. If outdoor advertising design concepts are experiencing difficulties from critics who never saw the good side of it, the hypothesis is simply that commercial business itself is in trouble. The study is therefore set to partition some experimental variables into factors that contribute to public misconception of graphic design concepts on billboard advertisements in Lagos State, Nigeria.

\section{Statement of the Problem}

Misconceptions about outdoor advertisements reflect a worrisome trend. Two schools of thought emerged about the issues of outdoor advertising. One regards it as being good while the other portrays it as unethical. Scholars like Jobber and Lancaster, (2009), Ingram, LarForge, Avila, SchwepkerJr and Williams, (2004), Biemans, (2010), and Blackwell, Miniard and Engel, (2006), agree that outdoor advertising is particularly effective in creating awareness among prospective clients. Blackwell (et al) point out that the effects of variables such as age, income, geography and in the particular case of Lagos State, religion are important to understanding why the public misconceive designs on outdoor bills. People do not have the same interpretative capacity for the connotation of design concepts. Additional understanding can be obtained by analyzing the ways in which individual differences such as personality, values and lifestyles affect public perception of design concepts. Of all types of advertising, the outdoor medium is criticized of numerous issues. Outdoor bills have the graphics spiffed up to attract the attention of its target audience, but the so-called graphics (design concepts) is misconstrued as misleading and deceiving the public into buying what is not needed. A number of value-decadent lifestyles of the youths are said to be as a result of the introduction of foreign cultures by the advertising agencies.

\section{Review of Related Literature}

\subsection{Meaning of Visual Design Concept}

Visual or pictorial design concept is a term that also relates to billboard advertisement and it means creative vision of art dimensions derived from imagination. It is an idea that brings diverse elements into a basic relationship (Ocvirk, Stinson, Wigg, Bone and Cayton, 2002). Design concept is considered as a visual image hinged on a thoughtfully selected theme for the purpose of communicating an idea to promote a product on a chosen platform. Product promotion itself is a form of advertisement put in place to sell firms' enterprise through informing, persuading and reminding the market (Kolawole, 2005). In every graphic design the dual function of a concept emerges. For instance, Monique Mosser in Porter and Naele, (2000), notes that on the one hand it serves the creative process and in the other hand, it is supposed to be an immediate comprehensible means of communication with non-specialists. The two are process and product respectively. Graphic design process and product are influenced by the type of concept which enables the subject matter to be understood and interpreted through the entire sequence of viewing, thinking, reasoning and decoding. Findings by Porter and Naele (ibid) demonstrate that both graphical and physical concepts have overtaken the progress of an unaided visualization. This assertion implies that there is always a concept underlying the images used in people-oriented outdoor advertisements. It also shows that design concepts are key issues in planning the form and determining the target audience of advertisements. Porter and Naele, (2000), opine that, 'design concepts encapsulate the essential spirit of a design response and can also capture the all-important first reaction that can sometimes remain as a captivator throughout the ensuing design journey' (p20). Design concepts have the tripod of visual form, reference to something and recognition by the audience as a concept.

\subsection{Use of Design Concepts in Outdoor Product Advertisements}

Even though there were works on advertising, marketing research and branding issues as fields of study, the available literature emphasized aspects that are completely different from the ongoing study. For instance, product marketing communication, promotion, re-branding strategies and sales return are areas dwelt into by majority of researchers. What about the visual force which designers put into each advertisement to meet some certain goals in the general marketing mix and which is encoded in the brain of passersby to raise awareness of products being campaigned? Researchers have always stressed more on the various 
economic theories for marketing. For instance, Bhatia, (2000), worked on 'Advertising in Rural India. The work centred on Language, Marketing Communication, and Consumerism at South West India, using 350 elements (Class Two pupils) as sample. In the study, statistical packages such as Mean, Standard Deviation, t-test and ANOVA were employed to analyse the data collected and the result of the study showed that there was a significant difference between course of study and rate of sale. Childers and Jass (2002), argued in a study that there is relationship between outdoor product advertising concepts and the rate of sales. The study sampled 300 advertisers. It applied descriptive research of the survey type to seek the opinions of the respondents. It employed correlation statistics mean, Standard Deviation and t-test for the analysis of the data collected. The study in both Bhatia, (2000), and Childers and Jass, (2002), dealt with rate of sales. However, their independent variables were course of study, advertising and product advertising respectively.

This present study is looking at the factors responsible for the misconception of graphic design concepts. Oelgeschlager, Hain, Ruiz and Sicilia, (2004), is another research that is all about impact of cognitive processing styles on consumer response to advertising appeals. Like Brennett, (2002), it dwelt a little bit on visual Graphic design to determine the influence of product advertising and promotion. The study collected data on 150 market women and 150 company workers and analysed it using descriptive statistics and t-test. It was discovered that there is difference between method of graphic design concept and product advertising appeal in majority of the companies used. Even though the studies have the same variables with the present study, they took place in Chicago. But this is not withstanding; the present study intends to find out whether the same or similar result will be obtained here in Nigeria even when the research design is not the same. Dodd, (2007), emphasized the commercial significance of outdoor advertising in urban community along rural highways in Georgia. Studies such as Adeyemi, (2002) and Makanju, (2005), have come up with findings on billboard advertising, specifically in Lagos State but did not mention what reasons the public has to criticize design concepts in the outdoor arena.

\subsection{Criticisms and Misconceptions About Outdoor Advertisements}

Inequalities that occur in the perception of the public about brand consultancies, multidisciplinary design offices, design boutiques, packaging industries are the same. It has left much issue to be resolved. Two schools of thought have so far been discovered in that regard. One portrays outdoor billboards advertising as being good while the other criticizes it. In Osunbiyi, (2002), it is revealed that the public attitude towards outdoor advertising is uncomplimentary and portraying the enterprise in bad light. Whereas, Tommy, (2009), is of the opinion that outdoor advertising is good, very successful and enjoyable business in the public domain. This means that so far the progress is impressive. Osunbiyi (op cit), maintains that the viewers of outdoor advertisements are fond of criticizing the enterprise as encouraging materialism, or placing all emphasis on acquisition of material things and perpetual consumption. A developing nation such as Nigeria should lay better emphasis on skill acquisition and production orientation, not material acquisition without being able to produce. This study sets to strike a balance between schools by investigating into the true position with particular reference to Lagos State, Nigeria. Other criticisms against advertising keep occurring. These, it was alleged that billboard messages and pictures encourage materialism, misuse of language, deception and exaggeration of product's efficiency. Osunbiyi (op cit), further explains that advertising misuses languages by deliberately distorting and debasing language lexis and structure just to deceive. This is a major criticism of advertising as noted by Osunbiyi (op cit), that it makes false claims, false testimony, and false comparison among others. It is observed that over-emphasis on product advertisement usually results in the public consumers paying more to buy such product.

Malickson and Nason, (1980), aver that it is not wellintentioned to blame societal ills such as sexual immorality, nudity, bad dressing, stealing and the drug addiction plaguing the modern society on billboard advertising. Terpstra, (1983) would however not subscribe to these opinions which it considered were premised upon false and inadequate information on the part of the public. However, advertising holds careerist values as well as professional ethics (Grunig and Hunt, 1984).Reece-Myron (1998), writes in favour of outdoor advertisement referring to it as an important communication which is inexpensive and reaching specific audiences by neighbourhood, it is a widely recognized medium which is cost effective. Nowadays, the outdoor advertising industry is widely offering splendid opportunities for both small business and huge companies. Besides, the outdoor is one of the fastest growing and developing directions in advertising which is normally emphasized in consumer marketing situations all over the globe (Ingram, LaForge, Avila, Schwepker Jr and Williams, 2004). The question here remains that if advertising is bad would it have been the spots of a keen demand for multinationaland indigenous companies (Telecommunications network industries, Beverages, Banking, etc) in Nigeria?

\section{Methodology}

\subsection{Factor Analysis}

The study is qualitative in nature and it adopts the research of the survey type. The sampling procedure used was'Pointof-sale' selection and randomization of samples (by gender) whose qualities and product experiences were considered most valuable to the study were purposively carried out. The analysis procedure used was Factor analysis by principal components which was adopted in the data analysis for the purpose of partitioning the experimental variables into factors that contribute to public misconception of graphic design concepts in outdoor advertisements. Also, the extent 
to which societal values influence consumer response to product promotion was investigated with the aid of factor analysis. Instrument used for this study consisted of variables numbered b48-b80. It centered on culture, morals, religion, taste and language. The purpose of factor analysis was to summarize inter-relationship and establish levels of variances in decision variables as they influence the given phenomenon. A factor is simply a linear combination of variables. The linear combination is not chosen arbitrarily, but to capture the relationship among the variables. Factor analysis uses the correlation or covariance among a set of observed variables to describe them in terms of smaller set of unobservable variables. The unobservable variables, called factors describe the underlining relationship among the original variables. Factor analysis requires a set of data points in matrix form with the row and column identifying the matrix (Olorunleke, 2006), and the model for it is given as:

$$
\begin{aligned}
& (\mathrm{Xí} \mid \hat{y}, \lambda, \mathrm{fí}, \mathrm{m})=\hat{\mathrm{y}}+\lambda \mathrm{fí}+\varepsilon^{\prime} \mathbf{i} \\
& (\mathrm{p} \times 1)(\mathrm{p} \times 1)(\mathrm{p} \times \mathrm{m})(\mathrm{m} \times 1)(\mathrm{p} \times 1)
\end{aligned}
$$

Where

$\hat{y}$ is the overall population mean vector

$\lambda$ is the factor-loading matrix

$\mathrm{f}_{\mathrm{i}} \mathrm{is}$ the factor score

$\mathrm{m}$ is the number of factors

$\mathrm{p}$ is the observed variables.

$\varepsilon_{i}$ is the error variance

${ }_{i}$ is the number of observation

\subsection{Specific Variables Used for theStudy}

B48 Materialism, b49 attraction of emotions, b50 deception, b51 encouragement of immorality, b52 springboard for negative vogues, b53 blasphemy, b54 corruption of the youths, b55 stimulation of unrestrained desire, b56 damage to culture, b57 dehumanizing, b58 violation, b59 indiscrimination, b60 persuasive, b61 enforcement of irrationality, b62 unnecessary emphasis, b63 encouragement of promiscuity, b64 insensitivity to sacred things, b65 irreligion, b66 debasement of the Language order, b67 infringement, b68 conviction, b69 crafty, b70 repeat contact, b71 imposition, b72 offence of the public taste, b73 bias, b74 emotional damage, b75 psychological damage, b76 unethical, b77 environmental pollution,b78 portrayal of females as mere sex objects, b79 distraction and b80 exaggeration.

\section{Results and Discussion}

\subsection{Analysis of Factors That Influence the Public Misconception of Design Concepts}

In making an enquiry into the factors that influence the public misconceptions of visual design concepts on outdoor billboard advertisements, Factor analysis by principal components was adopted in the data analysis for the purpose of partitioning of the variables into factors that influence the public misconception of design concepts. Thirty-three variables, numbered b48-b80 were identified for the purpose of this research.The variables were based on thirty-three questions that were designed to test the perception (the level of agreement or disagreement) of respondents on some important issues about design concepts and these capture the variables used for the factor analysis. The purpose of factor analysis in this research is to summarize inter-relationship and establish levels of variances in decision variables as they influence the given phenomena. A factor is simply a linear combination of variables. The analysis was done to reduce the variables into common factors.

Table 1. KMO and Bartlett's Test of Sampling Adequacy.

\begin{tabular}{lll}
\hline $\begin{array}{l}\text { Kaiser-Meyer-Olkin Measure of } \\
\text { Sampling Adequacy. }\end{array}$ & & $\mathbf{. 8 1 8}$ \\
\hline & Approx. Chi-Square & 2328.901 \\
Bartlett's Test of Sphericity & df & 528 \\
& Sig. & .000 \\
\hline
\end{tabular}

Table 1 shows that the sample is adequate because the $\mathrm{KMO}$ is 0.818 because any $\mathrm{KMO}$ value that is above 0.5 is considered adequate (Oluwadare, 2008, Alese and Owoyemi, 2006). The Bartlett's test is also significant at 0.05 level with $\mathrm{p}$ value of 0.00 .

\subsection{Communalities}

\begin{tabular}{|c|c|c|}
\hline Variable & Initial & Extraction \\
\hline $\mathrm{b} 48$ & 1.000 & .615 \\
\hline b49 & 1.000 & .628 \\
\hline b50 & 1.000 & .455 \\
\hline b51 & 1.000 & .475 \\
\hline b52 & 1.000 & .481 \\
\hline b53 & 1.000 & .541 \\
\hline b54 & 1.000 & .454 \\
\hline b55 & 1.000 & .483 \\
\hline b56 & 1.000 & .649 \\
\hline b57 & 1.000 & .585 \\
\hline b58 & 1.000 & .430 \\
\hline b59 & 1.000 & .535 \\
\hline b60 & 1.000 & .537 \\
\hline b61 & 1.000 & .549 \\
\hline b62 & 1.000 & .511 \\
\hline b63 & 1.000 & .606 \\
\hline b64 & 1.000 & .426 \\
\hline b65 & 1.000 & .563 \\
\hline b66 & 1.000 & .454 \\
\hline b67 & 1.000 & .618 \\
\hline b68 & 1.000 & .509 \\
\hline b69 & 1.000 & .579 \\
\hline b70 & 1.000 & .464 \\
\hline b71 & 1.000 & .513 \\
\hline b72 & 1.000 & .560 \\
\hline b73 & 1.000 & .445 \\
\hline b74 & 1.000 & .500 \\
\hline b75 & 1.000 & .610 \\
\hline b76 & 1.000 & .561 \\
\hline b77 & 1.000 & .609 \\
\hline b78 & 1.000 & .735 \\
\hline b79 & 1.000 & .596 \\
\hline b80 & 1.000 & .694 \\
\hline
\end{tabular}

Table 2. Communalities. 
The communalities are shown in Table 2 as the proportion of the variances explained by the common factors. The communalities are in the range 0 and 1 , with 0 indicating that the common factors (extracted) explained none of the variances in the variable and 1 indicating that the common factors explained all of the variances in the variable. It could also be expressed as a percentage. For instance, variable b48 (consumers' perception that advertising concepts place emphasis on material things) is 0.615 which indicates that $61.5 \%$ of the variances in the variable is accounted for by the common factors while the remaining $38.5 \%$ is accounted for by unique (unexplained) factors. The initial communalities are always 1.00 before the extraction of factors because at that initial stage every variable is regarded as a factor with a mean of 0 and standard deviation of 1 .

\subsection{Factor Extraction}

The 33 variables that influence public misconception of design concepts are subjected to factor extraction by principal component. The output of the analysis contains the initial component matrix which is subjected to rotation in order to fine-tune the loadings on each factor. The initial Eigen values, the percentage variance explained and the rotation sum of square loadings are presented in Table 3.

Table 3. Total variance explained (Rotation sums of squared loadings).

\begin{tabular}{|c|c|c|c|c|c|c|}
\hline \multirow{2}{*}{ Component } & \multicolumn{3}{|c|}{ Initial Eigen values } & \multicolumn{3}{|c|}{ Extraction Sums of Squared Loadings } \\
\hline & Total & $\%$ of Variance & Cumulative \% & Total & $\%$ of Variance & Cumulative \% \\
\hline 1 & 5.926 & 17.959 & 17.959 & 5.926 & 17.959 & 17.959 \\
\hline 2 & 2.224 & 6.740 & 24.698 & 2.224 & 6.740 & 24.698 \\
\hline 3 & 1.462 & 4.429 & 29.127 & 1.462 & 4.429 & 29.127 \\
\hline 4 & 1.379 & 4.178 & 33.305 & 1.379 & 4.178 & 33.305 \\
\hline 5 & 1.285 & 3.893 & 37.198 & 1.285 & 3.893 & 37.198 \\
\hline 6 & 1.238 & 3.751 & 40.949 & 1.238 & 3.751 & 40.949 \\
\hline 7 & 1.189 & 3.604 & 44.552 & 1.189 & 3.604 & 44.552 \\
\hline 8 & 1.130 & 3.424 & 47.977 & 1.130 & 3.424 & 47.977 \\
\hline 9 & 1.093 & 3.313 & 51.289 & 1.093 & 3.313 & 51.289 \\
\hline 10 & 1.046 & 3.169 & 54.459 & 1.046 & 3.169 & 54.459 \\
\hline 11 & .974 & 2.953 & 57.412 & & & \\
\hline 12 & .956 & 2.898 & 60.309 & & & \\
\hline 13 & .915 & 2.772 & 63.081 & & & \\
\hline 14 & .885 & 2.681 & 65.762 & & & \\
\hline 15 & .848 & 2.570 & 68.332 & & & \\
\hline 16 & .806 & 2.441 & 70.774 & & & \\
\hline 17 & .798 & 2.417 & 73.191 & & & \\
\hline 18 & .780 & 2.363 & 75.554 & & & \\
\hline 19 & .745 & 2.258 & 77.812 & & & \\
\hline 20 & .705 & 2.136 & 79.949 & & & \\
\hline 21 & .696 & 2.109 & 82.057 & & & \\
\hline 22 & .667 & 2.020 & 84.077 & & & \\
\hline 23 & .620 & 1.877 & 85.954 & & & \\
\hline 24 & .580 & 1.758 & 87.713 & & & \\
\hline 25 & .557 & 1.687 & 89.400 & & & \\
\hline 26 & .540 & 1.638 & 91.037 & & & \\
\hline 27 & .474 & 1.437 & 92.475 & & & \\
\hline 28 & .467 & 1.416 & 93.891 & & & \\
\hline 29 & .445 & 1.350 & 95.241 & & & \\
\hline 30 & .427 & 1.294 & 96.535 & & & \\
\hline 31 & .420 & 1.272 & 97.807 & & & \\
\hline 32 & .376 & 1.140 & 98.947 & & & \\
\hline 33 & .348 & 1.053 & 100.000 & & & \\
\hline
\end{tabular}

\subsection{Extraction Method: Principal Component Analysis}

The thirty-three (33) variables were reduced to ten (10) common factors after principal component analysis and factor rotation by varimax method. The ten factors account for $54.46 \%$ of the variances in the common factors. The remaining $45.54 \%$ are due to extraneous factors or variables not included in the model. The ten factors are extracted based on the rule that the components that have minimum of 1.0 
Eigen values should be extracted (Olorunleke, 2006; Alese and Owoyemi, 2006; Oluwadare, 2008).

Table 4. Rotated Component Matrix.

\begin{tabular}{|c|c|c|c|c|c|c|c|c|c|c|}
\hline \multirow{2}{*}{ Variable } & \multicolumn{10}{|c|}{ Component } \\
\hline & 1 & 2 & 3 & 4 & 5 & 6 & 7 & 8 & 9 & 10 \\
\hline $\mathrm{b} 60$ & .639 & & & & & & & & & \\
\hline b59 & .637 & & & & & & & & & \\
\hline b58 & .573 & & & & & & & & & \\
\hline b61 & .573 & & & & & & & & & \\
\hline b73 & .511 & & & & & & & & & \\
\hline b74 & .456 & & & & & & & & & \\
\hline b62 & .445 & & & & & & & & & \\
\hline b52 & & .615 & & & & & & & & \\
\hline b51 & & .602 & & & & & & & & \\
\hline b53 & & .574 & & & & & & & & \\
\hline b70 & & .492 & & & & & & & & \\
\hline b76 & & & .685 & & & & & & & \\
\hline b77 & & & .667 & & & & & & & \\
\hline b75 & & & .640 & & & & & & & \\
\hline b56 & & & & .722 & & & & & & \\
\hline b57 & & & & .580 & & & & & & \\
\hline b55 & & & & .570 & & & & & & \\
\hline b54 & & & & & .599 & & & & & \\
\hline b64 & & & & & .539 & & & & & \\
\hline b65 & & & & & .445 & & & & & \\
\hline b72 & & & & & .427 & & & & & \\
\hline b71 & & & & & .404 & & & & & \\
\hline b49 & & & & & & .709 & & & & \\
\hline b50 & & & & & & .541 & & & & \\
\hline b67 & & & & & & & .650 & & & \\
\hline b68 & & & & & & & .598 & & & \\
\hline b79 & & & & & & & .548 & & & \\
\hline $\mathrm{b} 80$ & & & & & & & & .798 & & \\
\hline b66 & & & & & & & & .441 & & \\
\hline b69 & & & & & & & & & .685 & \\
\hline b78 & & & & & & & & & & .752 \\
\hline b63 & & & & & & & & & & .467 \\
\hline b48 & & & & & & & & & & -.385 \\
\hline
\end{tabular}

Extraction Method: Principal Component Analysis. Rotation Method: Varimax with Kaiser Normalization.

A Rotation converged in 42 iterations.

Factor 1: Aesthetic appeal, religion and language.

Aesthetic appeal owing to the use of colour concept

Differences in spirituality/religion of the audience

Use of dehumanizing language which treat people as objects rather than human beings

Irrational purchase due to message concepts

Lack of appreciation of visual design concepts by religious organizations

Irrational purchase due to persuasive design concepts

Too much emphasis on consumption rather than production

Factor 2: Deceptive language, wrong impression and indecent use of the female gender

Use of deceptive copy to persuade consumers

Negative use of female gender to persuade consumers.

Use of negative vogues to persuade consumers.

Persuading consumers to believe that they need more products.

Factor 3: Emotional assault on consumer, deception and danger of reaching out to unintended audience.

Deception due to showing the only good side of a product.
Danger of reaching out to both intended and unintended audience.

Danger of psychological/emotional damage to the consumer.

Factor 4: Negative impact on the youths and stimulation of unrestrained desire for products

Youth vulnerability to culturally prohibited design concepts.

Stimulation of unrestrained desire for products.

Cultural effect of design concepts is homogeneous.

Factor 5: Blasphemous effect, desecration of sacred things and negative impact on public taste

Blasphemous effects due to animation

Insensitivity/lack of consideration to sacred things

Negative effect on minors

Negative effect on public taste

Static nature of billboards

Factor 6: Misleading effect of colour and advertising concepts

Use of colour concepts to stir consumers' emotions

Use of design concepts to deceive consumers to buy bad products.

Factor 7: Infringement on people's way of life and negative effect on culture 
Use of colour to appeal to the psychology of consumers

Use of design concepts which infringe on the people's way of life

Pollution of the environment with billboard structures.

Factor 8: Negative impact on language and culture due to use of slang

Damage to the material culture of the audience

Language disorder due to use of slang in advertising.

Factor 9: Compromise as a result of maintaining religious neutrality

Compromise by way of neutrality on religious teachings,

Factor 10: Unethical concepts in alcohol and cigarettes advertisement; and encouragement of materialism

Unethical concepts in the design of advertisement of cigarettes and alcohol

Negative effect of design concepts that encourages body movement

Encouragement of materialism.

Table 5. Percentage Contribution of Each Factor.

\begin{tabular}{ll}
\hline Total Variance Explained & Percentage Contribution \\
\hline 17.959 & 32.65 \\
6.74 & 12.26 \\
4.429 & 8.05 \\
4.178 & 7.60 \\
3.893 & 7.08 \\
3.751 & 6.82 \\
3.604 & 6.60 \\
3.424 & 6.23 \\
3.313 & 6.95 \\
3.169 & 5.76 \\
Total & 100.0 \\
\hline
\end{tabular}

From Table 5, it is noted that factor 1 accounts for $32.65 \%$ of the effect of visual design concepts on the culture, morals, religion, taste and language of the people, factor 2 contributes $12.26 \%$, factor 3 contributes $8.05 \%$, factor 4 contributes $7.60 \%$, factor 5 contributes 7.08 , factor 6 contributes $6.82 \%$, factor 7 contributes $6.60 \%$, factor 8 contributes $6.23 \%$, factor 9 contributes 6.95 while factor 10 contributes $5.76 \%$.

\section{Conclusion}

The study provides detailed phenomenological investigation into the factors responsible for wrong interpretation of the creative designs on outdoor bills in Lagos State, Nigeria. It is mentioned that everyone has had contacts with outdoor billboard advertisement at one time or the other. Product advertisements and all the paraphernalia (images, typography, colour, structure and location) surrounding it are catchy things that make undeniable impressions on the viewers. Examination of the methods of visual design concept (as stated in objective one) lends credence to the common knowledge that outdoor advertisement is the freest of all advertising media to view because it is erected freely in the open spaces where passersby can see it without having to pay or beg. Advanced models of outdoor bills are driven by electronic technology which enables the public to access information in styles of rhythms, synchrony and animation. Electronic messaging boards have their processing power in vast arrays of rhythmic colours and animation.

Critics may say that the billboard revolution came with its downside, which include distraction, deception, exaggeration, persuasion and stereotype, but the same information channel also possesses much prospect in an era of information and communication management. Thirty-three (33) variables were reduced to ten (10) common factors after principal component analysis and factor rotation by varimax method. The ten factors accounts for $54.46 \%$ of the variances in the common factors. The remaining $45.54 \%$ were due to extraneous factors or variables not included in the model. The ten factors were extracted based on the rule that the components that have minimum of 1.0 Eigen values should be extracted, however, it is observed that individual differences and variations in the perceptual ability of people that could be exposed to outdoor advertisements in Lagos has caused this misconceptions. This study reveals that while a few critics in Lagos have misgivings for the graphic concept of outdoor billboards, majority understand that advertising in one of the marketing mix necessary to make products and services known and patronized by the existing, potential and perhaps, the previous customers.

\section{References}

[1] Adeyemi, F. I. (2002): Billboards Innovation in Environmental Design, In Agberia J. T., (Ed) Design History in Nigeria (pp.191-198). Port Harcourt: Embai Press.

[2] Alese, B. K. and Owoyemi, S. O. (2004). Factor Analytic Approach to Internet Usage in South Western Nigeria. Journal of Information Technology Impact. 4, 3, 171- 188.

[3] Bhatia, T. K. (2000) Advertising in Rural India: Language, Marketing Communication, and Consumerism. Institute for the Study of Languages and Cultures of Asia and Africa. Tokyo University of Foreign Studies, Tokyo Press.

[4] Biemans, W. G. (2010). Business to business marketing: A value-driven approach, New York, McGraw-Hill Education.

[5] Blackwell, R. D., Miniard, P. W. and Engel, J. F. (2006). Consumer behavior, USA, Melissa Acuna.

[6] Brennett, A. (2002) Interactive Aesthetics. Design Issues, 18, $62-69$

[7] Childers, T. L., and Jass, J. (2002). All Dressed up with Something to Say: Effects of Typeface Semantics Associations on Brand Perceptions and Consumer Memory. Journal of Consumer Psychology, 12, 93-106.

[8] Dod, J. H. (2007) Outdoor Advertising In Urban Community Along Highways. Georgia, Georgia, Institute of Technology. A published Thesis http://hdl.handle.net/1853/20822. 
[9] Grunig, J and Hunt, T. (1984) Managing Public Relations, New York, Holt, Rinehart and Winston, 77-93.

[10] Hess, M and Doe, P. (2013). The Marketer's Dilemma: Focusing on a Target or a Demographic? The utility of Dataintegration Techniques. In Journal of Advertising, 53(2), 231236.

[11] Ingram, T. N. , La Forge, R. W., Avila, R. A., Schwepker, C. H. Jr. and Williams, M. R. (2004).

[12] Sales management: Analysis and decision making, 5th edition. USA, Thomson Southwestern.

[13] Jobber, D. and Lancaster, G. (2009). Selling and sales management, 8th edition, England, Pearson Education Limited.

[14] Kolawole, A. R. (2005) Marketing Mix, an Imperative for Quantity Surveying Practice. In International Journal of Business and Common Market Studies, Ikot-Ekpene, Vol. 3, No. 1, 21-25.

[15] Makanju, A. A. (2005): Outdoor Advertising: Evolution of Billboards in Lagos Metropolis. In Issues and Challenges of Creativity in Contemporary Nigerian Art Azees, W. A., et al (eds), Lagos, Anchor Creativities.201-209.

[16] Malickson, N. and Nason, J. W. (1985) Advertising: How to Write the Kind that Works. New York, John Willey and Sons Ltd.

[17] Ocvirk, O. G., Stinson, R. E., Wigg, P. R., Bone, R. O., and Cayton, D. L. (2002) Art Fundamentals - Theory and Practice, 9th Edition,USA, McGraw Hill.

[18] Oelgeschlager, G. \& Hain, Ruiz, S and Sicilia, M. (2004). The impact of cognitive and/or affective processing styles on consumer response to advertising appeals. Journal of Business research, 57, 657-664.
[19] Olorunleke, G. K. (2006). Managing Customer for Brand Equity in Carbonated Soft Drinks Market in Nigeria: A Case Study of Pepsi. Unpublished Ph.D Thesis, Dept. of Business Administration, University of Ilorin, Nigeria.

[20] Oluwadare, S. A. (2008). Performance Evaluation and Indices of Cyber Café Business: Factor Analytic Approach. Journal of Information and Communications Technology, University of Utara, Malaysia, 7, 4, 241 - 256.

[21] Osunbiyi, B. (2002) Contemporary Conflicting Issues in Advertising - Opening up the Debate Abeokuta, Jice Communication.

[22] Porter, T., and Naele, J. (2000) Architectural Super models: Physical Design Simulation, UK., Reed Educational and Professional Publishing Ltd.

[23] Precourt, G. (2013). What we know about Advertising. In Journal of Advertising, 53(2), 121-122.

[24] Reece - Myron, M. (1998): The Advantages of Outdoor Advertising. In The Denver Business Journal.

[25] Schneider, G. (2007). Electronic commerce, 7th annual edition, USA, Thompson Learning Inc.

[26] Terpstra, V. (1983) International Marketing - Third Edition. New York, CRS College Publishing.

[27] Tommy (2009) The History and Evolution of the Advertising Industry. An Internet Document http://www.advertisingcompanydirect.com Accessed 7 June 2009. 